\title{
$\mathrm{S}$ \\ Turismo e \\ Revista I UFPR
}

\section{Turismo em Ambientes Costeiros e o Combate ao Lixo no Mar}

\author{
Tourism in Coastal Environments and the combat of marine \\ litter
}

\section{Paula Turra Grechinski ${ }^{1}$ \\ Elieti Fátima Goveia²}

RESUMO: Este artigo tem o objetivo de discutir a relação entre o turismo em ambientes costeiros e o combate ao lixo que está no mar, um problema de proporções globais. O turismo convencional, entendido como atividade massiva e poluidora, também é responsável porgrande parcela do lixo descartado incorretamente e que chega aos oceanos, seja de forma direta ou indireta, mas a atividade turística pode também ser um agente de combate à poluição. Metodologicamente consiste em uma abordagem qualitativa, a partir de discussão teórica e casos emblemáticos de ações realizadas em destinos turísticos internacionais. A discussão aqui proposta está baseada na poluição do oceano em uma perspectiva socioambiental, utilizando, para tanto, de abordagens sobre a relação ser humano e turismo em ambientes costeiros. A partir dos resultados obtidos foi possível concluir que as iniciativas relacionadas ao combate ao lixo no mar em

\footnotetext{
1 Mestrado em Gestão do Território pela Universidade Estadual de Ponta Grossa (UEPG). Graduação em Turismo pela Universidade Estadual do Centro Oeste (Unicentro). Doutorado em andamento em Meio Ambiente e Desenvolvimento pela Universidade Federal do Paraná (UFPR). Docente no Departamento de Turismo da Unicentro. E-mail: paula.turismo@unicentro.br

2 Mestrado em Ciências Sociais Aplicadas pela Faculdades Reunidas de Administração, Ciências Contábeis e Econômicas de Palmas. Graduação em Ciências Econômicas pela Universidade Estadual de Ponta Grossa (UEPG). Docente e Chefe do Departamento de Turismo da Universidade Estadual do Centro Oeste (Unicentro). E-mail: elietigoveia27@hotmail.com
} 
destinos turísticos podem influenciar na mudança de hábitos de consumo da sociedade como um todo.

Palavras-chave: Turismo; Ambiente Costeiro; Lixo Marinho

ABSTRACT: This paper aims to discuss the relationship between tourism in coastal environments and the combat of marine litter, a global problem. The conventional tourism, understood as a massive and polluting activity, is also responsible for a large portion of the waste disposed in the oceans, either directly or indirectly, but the activity can also be an agent to combat pollution. It consists in a qualitative approach, based on theoretical discussion and iconic cases of actions carried out in international tourist destinations around the world. The discussion proposed in this study was based on ocean pollution from a socio-environmental perspective, using approaches on the relationship between human beings and tourism in coastal environments. From the results obtained, it was possible to conclude that the initiatives related to combat of marine litter in tourist destinations can influence the change in consumption habits of the society as a whole.

Keywords: Tourism; Coastal Environment; Marine Litter 


\section{INTRODUÇÃO}

Esse artigo aborda um problema socioambiental que gera uma série de ameaças para a saúde pública e o ambiente, atingindo o planeta como um todo: o lixo no mar. De acordo com a Estratégia de Honolulu, documento resultante da $5^{\text {a }}$ Conferência Internacional de Lixo Marinho (International Marine Debris Conference, IMDC), o lixo no mar pode resultar de atividades em terra ou no mar, e consiste em qualquer material sólido (independentemente do tamanho) antropogênico, manufaturado ou processado que foi descartado, disposto ou abandonado no ambiente, incluindo todos os materiais descartados para o mar, na costa, ou trazidos indiretamente pelos rios, esgotos, águas pluviais, ondas, ou ventos (IMDC, 2011).

O objetivo desta pesquisa consiste em discutir a relação entre o turismo em ambientes costeiros e o combate ao lixo que está no mar. Esta discussão emerge de uma constatação empírica da pesquisadora ao observar que destinos turísticos costeiros em diferentes lugares do mundo estão realizando ações (sejam iniciativas públicas ou privadas) para informar e sensibilizar as pessoas com relação ao lixo no mar. Empreendimentos hoteleiros, terminais de transportes, bares e restaurantes, e outros componentes da oferta turística estão chamando a atenção dos turistas para o problema, que tem sido cada vez mais discutido em âmbito global. Algumas ações são aqui apresentadas.

Entende-se que a atividade turística gera impactos relevantes no ambiente costeiro, especialmente devido ao adensamento populacional sazonal e à visitação massiva de turistas durante os meses de verão. Em llhabela (SP), a população passa de 40 mil para 120 mil habitantes durante a temporada de veraneio (FREDIANI, 2020). Em Guaratuba (PR), segundo informações do $8^{\circ}$ Grupamento de Bombeiros ${ }^{1}\left(8^{\circ} \mathrm{GB}\right)$, a população sobe de 35.000 para 300.000 a 350.000 durante uma temporada. Os estudos de Santos e Cândido (2013) sobre a praia de Porto de Galinhas (PE), apontam alguns exemplos dos impactos ocasionados pela atividade turística sazonal: falta de água; poluição visual; poluição das águas do mar; consumo de energia; ausência de tratamento de esgoto; aumento da poluição do ar em decorrência da maior circulação de veículos motorizados e aumento significativo na geração de resíduos sólidos e sua incorreta destinação final.

Porém a atividade turística também pode trazer impactos positivos, como a valorização da cultura, a proteção do patrimônio natural e a valorização de edificações históricas. Diversas pesquisas abordaram essas relações, trazendo tanto o impacto positivo quanto o impacto negativo do turismo em diferentes situações (CUNHA e CUNHA, 2005; BRUDEKI, 2006; MEDEIROS e MORAIS, 2013; SAMPAIO e ZAMIGNAN, 2012).

Nessa pesquisa entende-se que o problema do lixo no mar é reflexo da ação humana derivado das formas de produção e consumo anteriores e atuais. Em

1 Informação concedida à autora pelo Comandante do $8^{\circ}$ Grupamento de Bombeiros ( $8^{\circ}$ GB), major Emmanuel Benghi Pinto, em entrevista informal realizada em 10 de janeiro de 2020. 
outras palavras, os impactos ambientais para os quais se buscam alternativas estão relacionados a padrões sociais de produção e consumo insustentáveis, inclusive no turismo (ALVARES, 2010). E aqui se considera também que o turismo em ambientes costeiros pode representar uma estratégia para chamar atenção sobre o problema do lixo no mar.

Destaca-se neste trabalho o quanto é necessário o comprometimento do ser humano com atitudes que minimizem os impactos negativos de suas ações, inclusive e especialmente quando estão realizando viagens e desfrutando de seu tempo livre em um local que não é de sua residência habitual. Sendo assim, os impactos socioambientais do lixo no mar considerados nesta discussão consistem no resultado das ações antrópicas não apenas quando estão nas praias e balneários durante suas atividades recreativas, mas em todas as ações, ou mesmo nas omissões, do comportamento humano, advindas da produção, consumo e descarte.

\section{MATERIAIS E MÉTODOS}

Para atingir o objetivo proposto, realizou-se levantamento de referencial teórico, levantamento de dados secundários em fontes oficiais, e pesquisa documental em publicações nacionais e internacionais, apresentando assim alguns dados referentes ao cenário global e local referente ao lixo no mar. Os dados secundários foram obtidos em pesquisa online em sites da Organização das Nações Unidas (ONU 2018; 2019) e da Marine Litter Network (2019) e os documentos consultados foram a Estratégia de Honolulu (IMDC, 2011); e o relatório Global Waste Management Outlook, da UNESCO (UNEP, 2015).

Em uma terceira etapa de pesquisa, enfatizou-se a busca por iniciativas existentes em destinos turísticos costeiros. Dentre os destinos turísticos costeiros que apresentam iniciativas de combate ao lixo no mar, e cujos exemplos encontramse neste trabalho estão: Maresias, no litoral norte do Estado de São Paulo (Brasil); a Ilha da Culatra, na região costeira do Algarve (Portugal); e com maior destaque a Ilha de Bali, na Indonésia. Esta llha (cuja atividade principal é o turismo) tem sido referência em estudos e práticas que dizem respeito à necessidade urgente de soluções para o grande volume de resíduos em ambientes costeiros, especialmente o plástico.

Observou-se in loco que nos três destinos citados existem iniciativas que informam turistas e visitantes sobre o lixo no mar, na tentativa de sensibilizá-los com relação a este problema. As informações referentes às iniciativas dos destinos turísticos que contribuem para o combate ao lixo no mar foram obtidas em campo, sendo: a Ilha da Culatra visitada em novembro de 2014; a llha de Bali em outubro de 2019; e Maresias (SP) em novembro de 2019.

Para a estruturação do artigo, a abordagem inicia-se com informações relacionadas às causas e consequências do lixo no mar, possibilitando um melhor entendimento a respeito desse problema. Depois, o tema é contextualizado com informações referentes ao combate ao lixo no mar. Por fim, apresentam-se ações empreendidas em diferentes destinos do mundo, possibilitando concluir sobre como 
o turismo em ambientes costeiros pode contribuir para o combate ao lixo que está no mar.

\section{REFERENCIAL TEÓRICO}

O referencial teórico deste trabalho aborda as causas e consequências do lixo no mar, e como combatê-lo. Sendo assim, utiliza-se como referências teóricas Leff (2014), ao compreender a forma com que o homem se relaciona com a natureza como consequência também de seus padrões de consumo e modos de vida. Giddens (2001) é utilizado como referência ao abordar a relação humana e o ambiente em seus estudos. No âmbito do turismo, a pesquisa utilizou como referência pesquisas de autores que relacionam temas socioambientais ao turismo como Alvares (2010) e Espínola, Ferreira e Marques Junior (2020).

\subsection{O LIXO NO MAR: CAUSAS E CONSEQUÊNCIAS}

O problema ambiental do lixo no mar pode ser considerado uma questão social, cultural e da vida em sociedade; pois é resultado das transformações vividas pela humanidade (sejam elas econômicas, políticas, culturais ou institucionais). De maneira geral, os problemas que enfrentados com o lixo no mar estão originados em fatores como práticas inadequadas, falta de infraestrutura para gestão dos resíduos, produtos que foram desenhados sem se considerar os impactos do seu ciclo de vida, escolhas do consumidor, perda acidental ou deliberada de utensílios de pesca e resíduos de navios, e a pouca compressão das pessoas sobre as consequências de suas ações (IMDC, 2011).

Leff (2014), ao abordar o mundo social moderno destaca que as ideologias voltadas unicamente ao progresso e crescimento têm grande impacto na natureza, apresentando-as como uma cultura de risco pela forma como o mundo social se organiza de maneira dissociada da preservação do meio ambiente. Giddens (2001) menciona que não é possível fazer generalizações sobre o comportamento humano, mas uma das características observadas pela ciência social ortodoxa é o fato de não termos consciência do porquê fazemos as coisas e nossas atitudes, a chamada causação social. O consumo desenfreado, por exemplo, tem resultado em uma grande dificuldade de gerir os resíduos gerados pela população mundial. De acordo com relatório da United Nations Environment Program (UNEP, 2015), nos últimos 50 anos houve um aumento exponencial do uso de recursos naturais, na produção e consumo, levando a uma degradação ambiental e acarretando intensa transformação na relação seres humanos e natureza.

O modo de pensar a sociedade está completamente relacionado ao modo como nos aliamos à natureza ou à desprezamos cotidianamente (LEFF, 2014). Ao atentar para a existência do problema específico do lixo no mar, por exemplo, é momento de agir no sentido de uma mudança que é também social. Estimativas apontam que "[ ] se não for diminuído o ritmo com que se descartam itens como garrafas plásticas, 
sacolas e copos depois de um único uso, até 2050, os oceanos terão mais plásticos que peixes" (ONU, 2018, [s/p]).

Vale refletir que, de maneira geral e em diferentes partes do planeta, a população apresenta um estilo de vida cujos padrões gerais de consumo - fortemente influenciados pela indústria - relacionam-se à embalagens leves e produtos de uso único. Com a falta de um plano de gestão dos resíduos, boa parte deles têm ido parar no mar, ocasionando diversos tipos de impactos para o ambiente natural e os ecossistemas como um todo - fato este que apenas recentemente, e aos poucos, tem sensibilizado a população mundial apesar de já terem sido apresentados por cientistas há algumas décadas. Este é um problema complexo, que deve ser tratado de forma holística e abrangente, pois apenas um setor ou campo da ciência não resolverá o problema (ALVARES, 2010).

Quanto às consequências, o lixo no mar pode causar um amplo e variado número de impactos sejam eles ambientais, econômicos e sociais. Estes impactos foram apresentados na $5^{\mathrm{a}}$ Conferência Internacional de Detritos Marinhos, realizada em 2011 no Hawaii, e resultaram no documento intitulado Estratégia de Honolulu. Este documento representa um esforço abrangente e global para reduzir os impactos do lixo nos oceanos, podendo ser instrumento de guia e apoio aos processos globais, nacionais e regionais para abordar o problema do lixo marinho (IMDC, 2011). De forma bastante resumida, alguns impactos ocasionados pelo lixo no mar são: emaranhamento de animais marinhos e ingestão de itens de plástico; destruição, alteração ou degradação do habitat e declínio das populações de vida marinha; concentração de poluentes no ambiente aquático; introdução e disseminação de espécies invasoras; pesca fantasma; avarias em embarcações; degradação da qualidade estética das praias e zonas costeiras, dissuadindo visitantes e resultando em menos negócios e lucros para a comunidade costeira; e riscos para a saúde pública e segurança humana (IMDC, 2011).

\subsection{COMO COMBATER O LIXO NO MAR}

Em âmbito internacional, uma das referências para o combate ao lixo no mar é a Estratégia de Honolulu (IMDC, 2011). Nela, constam três objetivos que podem contribuir para reduzir a ameaça do lixo no mar: 1 - reduzir a quantidade e impacto do lixo e resíduos sólidos produzidos em terra e introduzidos no ambiente marinho (exemplo de ação: a proibição de sacolas plásticas); 2 - reduzir a quantidade e impacto de fontes de detrito marinho produzidas no mar (resíduos sólidos, cargas perdidas e embarcações abandonadas); e 3 - reduzir a quantidade e impacto de detritos acumulados nas orlas costeiras, habitats bentônicos e águas pelágicas (exemplo de ação: mutirões de limpeza de praia).

Também dentre as ações que envolvem turismo, lixo no mar e sustentabilidade, empreendidas em âmbito global, destaca-se a promoção dos Objetivos de Desenvolvimento Sustentável (ODS) no setor de viagens e turismo, buscando o engajamento da atividade turística às metas da agenda global de desenvolvimento 
sustentável (OMT, 2020) e o turismo em uma perspectiva que contribui para o alcance do desenvolvimento sustentável. A relação entre o turismo e o lixo no mar pode ser observada de forma direta e expressa no ODS 14 - Vida na água: Conservação e uso sustentável dos oceanos, dos mares e dos recursos marinhos para o desenvolvimento sustentável, na Meta 14.7:

Até 2030, aumentar os benefícios econômicos para os pequenos Estados insulares em desenvolvimento e os países menos desenvolvidos, a partir do uso sustentável dos recursos marinhos, inclusive por meio de uma gestão sustentável da pesquisa, aquicultura e turismo (ONU, 2015, p. 28).

No Brasil, a Política Nacional de Resíduos Sólidos instituída pela Lei 12.305, de 02 de agosto de 2010 já considerava a importância de ações para combater o lixo no mar (BRASIL, 2010). Porém, de maneira mais específica, o Plano Nacional de Combate ao Lixo no Mar lançado em 2019 apresenta estratégias de combate ao lixo no mar para o país, como a retirada dos resíduos na forma de mutirões de limpeza de praia; e ações de educação ambiental para prevenir o lixo no mar (BRASIL, 2019).

Foi a partir de 2017, após o lançamento do programa global Clean Seas (Mares Limpos) pela ONU durante a Cúpula Global dos Oceanos em Bali, Indonésia que, diversas ONGs, pesquisadores, empresas, governos e cidadãos do mundo todo passaram a realizar ações para proteção ao ambiente marítimo e costeiro. Dentre essas ações, encontra-se uma mudança de comportamento do consumidor, a busca e introdução de novas tecnologias, a implementação e aplicação de planos, políticas e leis para alterar a produção, uso e gestão de resíduos.

$\mathrm{Na}$ ocasião do lançamento do Programa citado, foram apresentados dados alarmantes com relação ao impacto do lixo no oceano, especialmente o plástico. $O$ Programa incentiva, portanto, a elaboração de políticas de proteção aos ecossistemas marinhos, recomenda às empresas que reduzam a produção de embalagens plásticas, e convoca consumidores a mudar o modo como descartam o lixo. A intenção da ONU é que até o ano de 2022, seja revertido o processo de poluição dos oceanos e suas consequências para a vida marinha (ONU, 2018).

Setenta e cinco países, inclusive o Brasil, aderiram à iniciativa e se comprometeram a combater os plásticos descartáveis e incentivar a reciclagem. Esta é, segundo a ONU (2019), a maior aliança mundial para combater a poluição marinha por plástico, abrangendo $60 \%$ dos litorais do mundo. Importante mencionar que antes do programa Mares Limpos houveram outras iniciativas importantes que alertaram sobre o problema que emerge há algum tempo, embora sem a repercussão e força de mídia que se observa atualmente.

Outro Programa que pode ser destacado no contexto deste trabalho, é o Bandeira Azul. Consiste em uma certificação que indica a qualidade ambiental de praias e marinas brasileiras e pode ser considerada um diferencial na gestão de destinos turísticos (ESPÍNOLA, FERREIRA \& MARQUES JUNIOR, 2020). 
Para discutir o combate ao lixo no mar é importante considerar a existência de diferentes perspectivas e atores envolvidos, pois determinadas políticas ou instituições legais podem ser bem sucedidas na prevenção da poluição em um contexto, mas em outro não (IMDC, 2011). De qualquer forma, Franz (2011) afirma que a prevenção quanto à geração de lixo no mar é menos custosa e mais eficiente do que as ações de remediação. Também há que se considerar que, alguns dos atores envolvidos podem ter um melhor entendimento para aderir à iniciativa de mudar seu comportamento e modos de produção e consumo, e outros não (IMDC, 2011).

Com relação ao turismo, este é considerado uma das quatro principais fontes terrestres de lixo no mar, juntamente com vazadouros de lixo localizados em área costeira, transporte fluvial de resíduos para aterros, e descargas de esgotos não tratados (FRANZ, 2011). Cabe, portanto, também à oferta e demanda turística a responsabilidade pela conscientização e monitoramento das ações mitigadoras deste impacto derivado de suas atividades.

É difícil estabelecer metas ou afirmar quais ações reduzirão o lixo no mar, pois isso depende de contextos sociais, culturais, ambientais e econômicas sobre o qual as metas e ações são planejadas e implementadas (IMDC, 2011). De qualquer forma, é importante perceber a relação de responsabilidade compartilhada entre estado, mercado e sociedade civil e o quanto um influencia no outro, tendo impactos diretos e indiretos, seja na produção, consumo ou gestão do lixo no mar. Do mesmo modo, todos devem também contribuir para implementar soluções para reduzir ou prevenir o lixo no mar, sendo que o papel e importância de cada um dos atores, e sua contribuição para as soluções, dependerão do contexto particular e processo educativo em que o problema é abordado.

\section{RESULTADOS: DESTINOS TURÍSTICOS E O COMBATE AO LIXO NO MAR}

O turista que busca desfrutar de um período de tempo em um destino costeiro, o faz devido ao ambiente esteticamente belo do litoral e propício às atividades de lazer e descanso (PIERRI et.al., 2006). E, se lhe agrada este ambiente para desfrutar de seu tempo livre e ocioso, parece ser também uma boa ocasião para o sensibilizar sobre os problemas que este ambiente enfrenta. Talvez ali, ao desfrutar de suas férias em um destino turístico costeiro, e em contato direto com o oceano, as campanhas e ações de sensibilização referentes à proteção deste ambiente possam surtir efeito mais impactante, demonstrando ao turista que ele contribui diariamente para o lixo que está indo parar no mar, independente do fato de estar na praia ou em seu local de residência.

A seguir serão apresentados os casos analisados de destinos turísticos costeiros que apresentam ações no sentido de informar/sensibilizar os turistas e visitantes com relação à existência de lixo no mar.

A llha de Bali, na Indonésia, considerada uma das 10 melhores ilhas turísticas do mundo, tem no turismo $80 \%$ de seu Produto Interno Bruto (BAKER, 2003). Observouse durante a pesquisa de campo, que este destino está preocupado em mostrar para 
todos aqueles que o visitam, que o lixo que está no mar - e o lixo que vem do mar - é um problema de todos, não apenas quando estão na ilha, mas também em seu local de origem.

O movimento mundial para a não utilização de sacolas plásticas teve origem em 2013 com o movimento Bye Bye Plastic Bags na Indonésia, onde foi proibido o uso de sacolas plásticas. A figura 01 apresenta um estande informativo sobre esta questão no Aeroporto Internacional NgurahRai, em Bali.

\section{FIGURA 1: INFORMAÇÃO AEROPORTO DENPASAR, INDONESIA.}

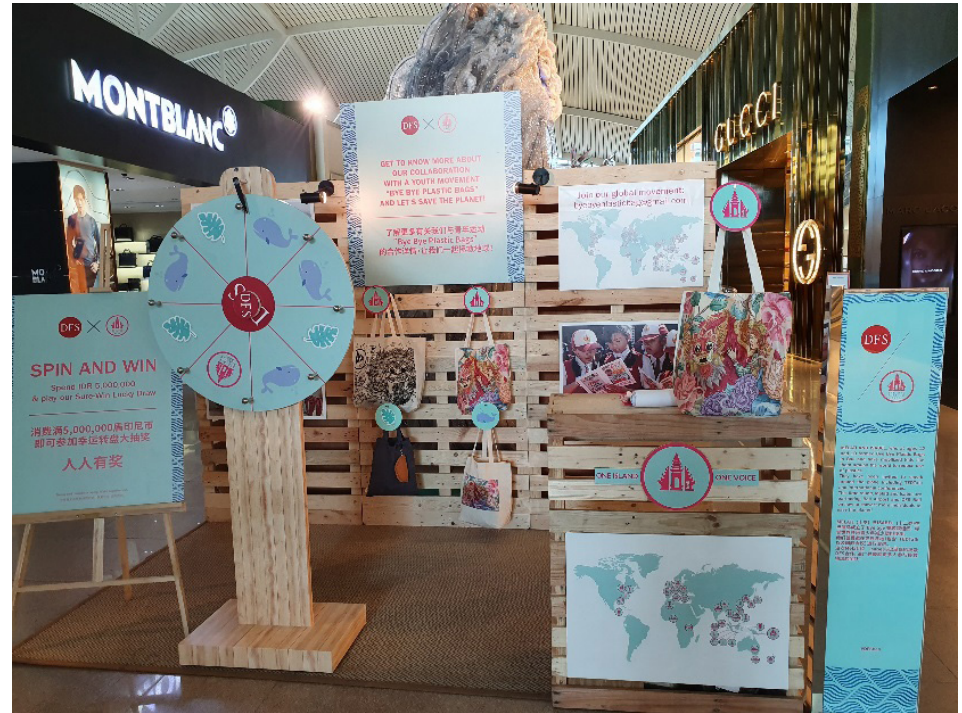

FONTE: Acervo pessoal (2019)

O estande apresenta ao turista, de forma objetiva, o que é a iniciativa Bye Bye Plastic Bags e convida-o a se informar e contribuir não utilizando sacolas plásticas. Em uma das placas que aparecem na Figura 01 consta o seguinte texto: "Melati e Isabel, com idade de 12 e 10 anos, fundaram a Bye Bye Plastic Bags em Bali e mobilizaram crianças como elas em todo o mundo a reduzir o uso de plásticos. Elas foram convidadas a falar para o mundo inclusive no TED Talk e em conferências internacionais. Dessa vez, Melati e Isabel são parceiras no Aeroporto de Bali e DFS Bali para convidar mais pessoas a salvar o planeta!" (tradução nossa).

Em outra placa, a seguinte mensagem: "Saiba mais sobre nosso apoio ao movimento jovem "Bye Bye Plastic Bags" e vamos salvar o planeta!" (tradução nossa). Além de mapas ilustrando a expansão do movimento para outros locais do planeta e informações de contato, também há uma placa indicando que esta ação faz parte do coletivo One Island One Voice, uma rede de organizações ativas no campo de prevenção e gestão de resíduos, cuja base é em Bali. 
Outra ação observada no mesmo aeroporto, vale frisar a importância deste terminal enquanto ponto de chegada e partida de todos os turistas na llha, é uma obra de arte feita com garrafas e tampinhas plásticas representando uma 'onda de plástico'. Além do impacto visual da arte em si, a estrutura contém tecnologia que movimenta a onda, chamando atenção para a questão exposta (Figura 02). Ao lado da obra, além de informações sobre os artistas Marmar e Monez, encontra-se o seguinte texto "Com a recente proibição oficial do plástico descartável (uso único) em Bali, nossa equipe teve a ideia de colaborar com três personalidades balinesas para comunicar essa mensagem no aeroporto de Bali. Bali é conhecida por suas lindas praias e com esse projeto nós estamos juntos levando a público essa fantástica instalação artística feita com resíduos de plástico." (tradução nossa).

\section{FIGURA 2: ARTE EM 3D ARTISTAS MARMAR E MONEZ.}

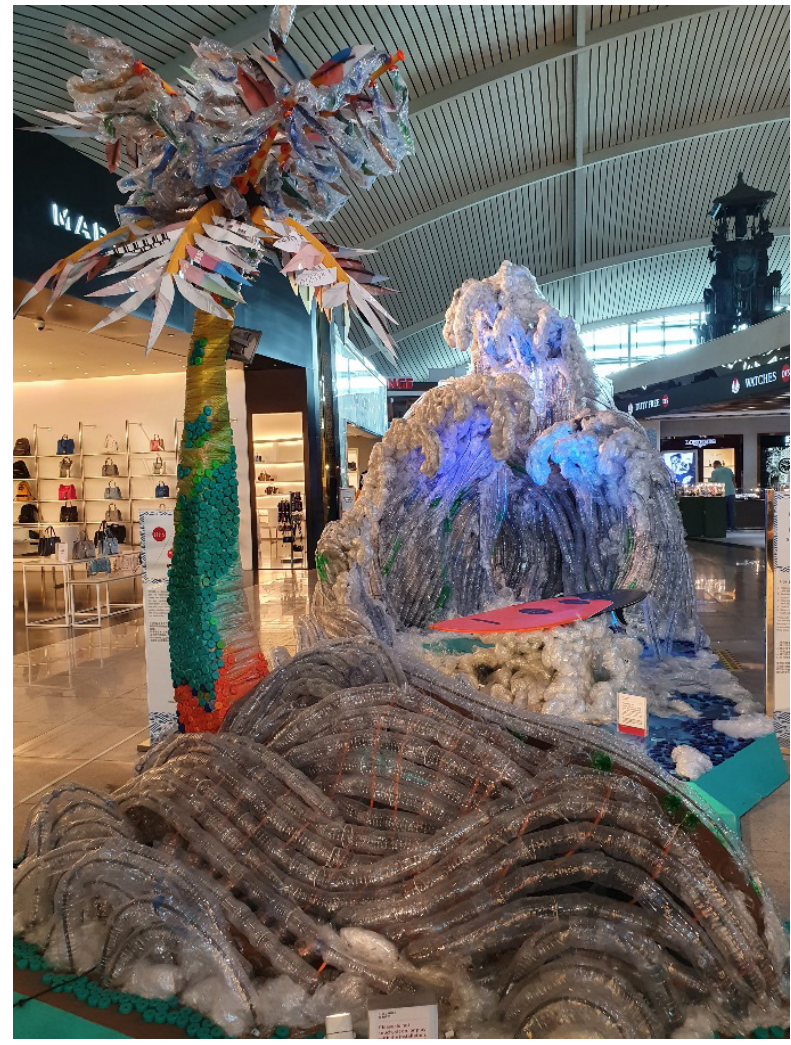

FONTE: Acervo pessoal (2019)

Além das informações no aeroporto, observam-se outras iniciativas de combate ao lixo no mar. Em Keramas, o Komune Resort instalou uma barreira de contenção no rio que corta o empreendimento, para evitar que resíduos carregados pelo rio cheguem até o mar (Figura 03). 


\section{FIGURA 3: KOMUNE RESORT}

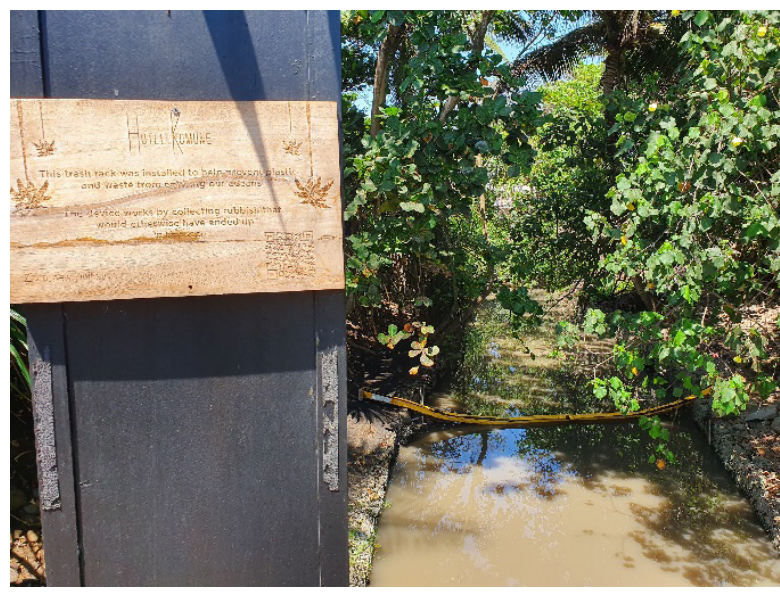

FONTE: Acervo pessoal (2019)

Na placa, a mensagem "Esta barreira para o lixo foi instalada para prevenir a entrada de plástico e outros resíduos no oceano. O dispositivo funciona coletando o lixo que, de outra forma, teria acabado no mar." (tradução nossa). Ressalta-se o fato mencionado de que o lixo que está no mar não é necessariamente deixado pelas pessoas que estão na praia e não destinaram corretamente seus resíduos. O lixo que está no mar vem também de regiões centrais, levados para o mar através dos rios, e a iniciativa deste resort em colocar a placa, informa o turista a respeito dessa situação.

O lixo no mar também tem sido abordado de forma paralela em eventos com movimentação turística. É o caso da etapa do campeonato mundial de surf que ocorreu em maio de 2019 em Bali, com o nome Corona Bali Protected. Na ocasião, um projeto piloto foi colocado em prática com o objetivo de chamar a atenção para o problema ambiental global da poluição dos oceanos por plástico, convidando a todos a se comprometerem e se unirem na tarefa de evitar plástico, interceptar detritos de plástico, e redesenhar materiais e produtos. As ações empreendidas consistiram em mutirões de limpeza de praia, experiências imersivas e educativas sobre como o plástico está destruindo os ambientes naturais e como consumidores, indústrias e marcas podem contribui para solucionar a questão, palestras educativas com a presença de atletas e personalidades reconhecidas, apresentação de produtos feitos com materiais reciclados e eco-inovadores, eventos $100 \%$ livre de uso de plástico não reciclável e programas de reciclagem.

Empreendimentos hoteleiros e casas noturnas também incentivam seus consumidores a participar de mutirões de limpeza de praias. É o caso do Old Man's, a principal casa de shows localizada em Canggu, Bali. Este empreendimento convida voluntários, através de suas redes sociais, para participar semanalmente de mutirões de limpeza realizado em parceria com diversos outros restaurantes e bares da localidade. A Figura 04 mostra uma faixa anunciando o ponto de encontro dos participantes antes e depois da realização da coleta de resíduos na areia. 


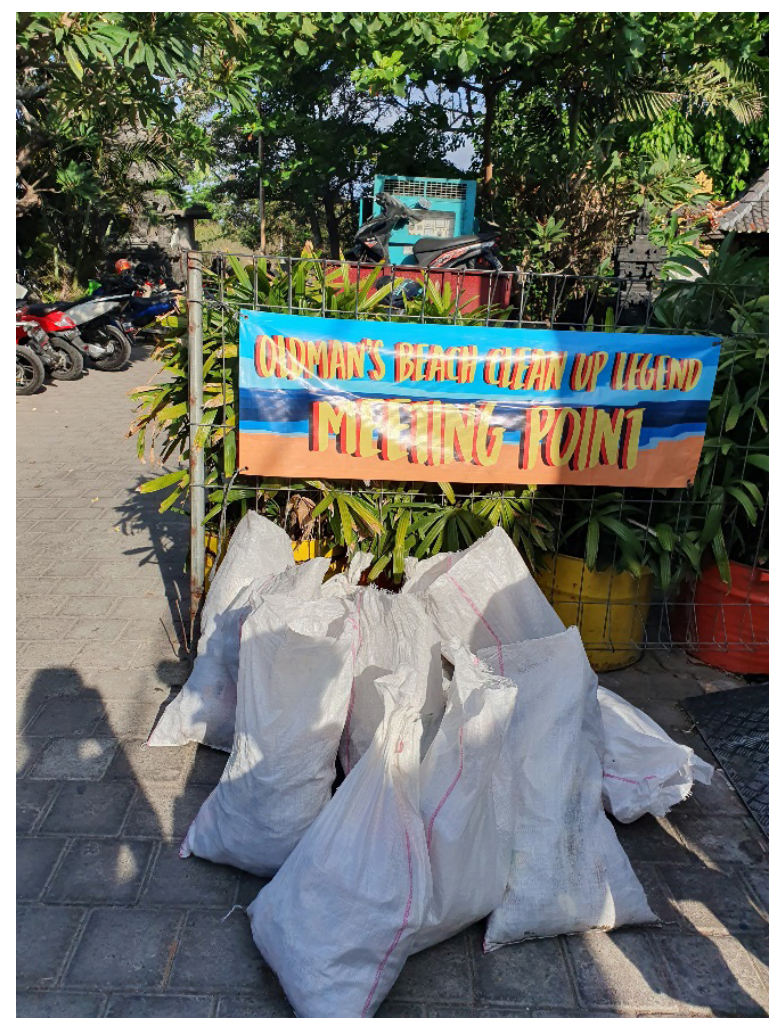

FONTE: Acervo pessoal (2019)

Ainda na Indonésia, nas Ilhas Gili, ao caminhar pela areia o turista tem sua atenção chamada para uma estrutura de uma imensa tartaruga (Figura 05) com a seguinte mensagem "Me alimente com suas garrafas de plástico. Mantenha as praias de Gili limpas e livres de plástico" (tradução nossa).

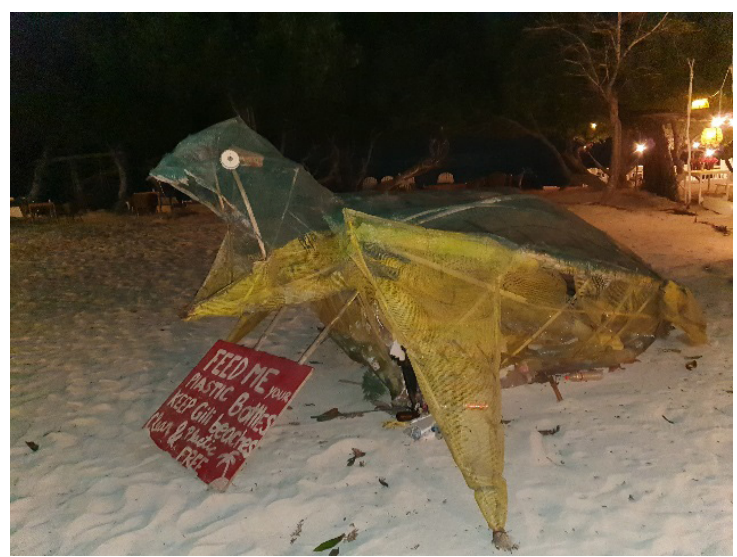

FONTE: Acervo pessoal (2019) 
Neste exemplo, o problema do lixo no mar é abordado de forma educativa com relação ao correto destino dos resíduos. Ainda assim, pode configurar e ser abordado no sentido de impactar o turista com relação ao quanto o plástico tem sido prejudicial para a vida marinha e ecossistemas, uma vez que, diferente de uma lixeira e um cartaz induzindo à correta destinação de resíduos, se utiliza de uma estrutura no formato de um animal marinho sendo alimentado com garrafas plásticas.

Ações semelhantes a esta, chamando a atenção do turista para que não deixe resíduos nas praias, são encontradas em diversas praias no mundo todo. A llha da Culatra, ao sul de Portugal, está localizada em uma área protegida e abriga mil habitantes permanentes e recebe mais de 7.500 turistas/dia no verão. $O$ turismo representa a segunda atividade econômica para a população da ilha, que tem como primeira atividade a pesca (GUERREIRO \& PACHECO, 2020).

A Ilha da Culatra faz parte de um projeto piloto em energias renováveis, o Projeto Culatra 2030 - Comunidade Energética Sustentável. Um exemplo das ações do Projeto é a implantação da ação de dessalinização da água do mar, ação que já tem sido utilizada pela hotelaria na região do Algarve onde a llha está situada (GUERREIRO \& PACHECO, 2020). Em 2020 a referida ilha passou a integrar um projeto de turismo sustentável que envolve 14 regiões europeias, nominado 'SuSTowns: Turismo Sustentável em pequenos e fascinantes povoados da área Mediterrânica' (SUSTOWNS, 2021).

Dentre os exemplos que contribuem direta ou indiretamente para o combate ao lixo no mar, a llha oferece cinzeiros aos turistas para evitar que os mesmos deixem filtros de cigarro (popularmente chamados bitucas no Brasil e beatas em Portugal), na praia (Figura 06).

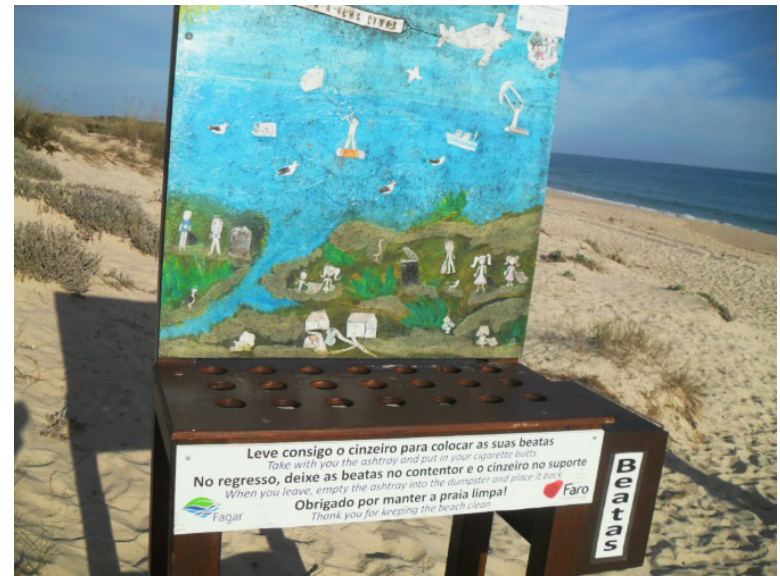

FONTE: Acervo pessoal (2014) 
Na mensagem, o seguinte texto em português e inglês "Leve consigo o cinzeiro para colocar suas beatas. No regresso, deixe as beatas no contentor e o cinzeiro no suporte. Obrigado por manter a praia limpa!". Por outro lado, Oliveira e Costa (2020) destacam o uso frequente de utensílios plásticos entre a população local residente na llha e a indústria turística como algo negativo no que diz respeito a atitudes que beneficiem o ambiente costeiro.

Ação semelhante aos cinzeiros na llha da Culatra é realizada no litoral norte do Estado de São Paulo (Ilhabela, São Sebastião e Juquehy) em uma parceria entre a oferta turística (hotéis, restaurantes e condomínios), e a primeira usina de reciclagem de bitucas do Brasil, a Poiato Recicla (POIATO RECICLA, 2018; FREDIANI, 2020). Esta responsabiliza-se pela disponibilização das caixas coletoras nas praias e posterior coleta e reciclagem das bitucas, enquanto os empreendimentos turísticos apóiam a campanha e sensibilizam os turistas, especialmente em feriados e alta temporada.

Um estudo da Associação Brasileira de Empresas de Limpeza Pública e Resíduos Especiais (ABRELPE) apontou que as bitucas de cigarro compõem a maior parte do lixo nas praias do Brasil (VELIS et.al., 2017). Outros exemplos de resíduos mais encontrados são tampas de garrafa pet, hastes flexíveis (cotonetes), isopor e lacres de latas (FREDIANI, 2020).

Em Maresias (estado de São Paulo - SP), além do projeto de sensibilização com relação aos resíduos dos fumantes citado, é possível observar outros tipos de ações e campanhas informativas de sensibilização. Como exemplo, a Figura 07 apresenta uma placa informativa onde se lê "Plástico descartado indevidamente é uma das causas da morte de animais marinhos".

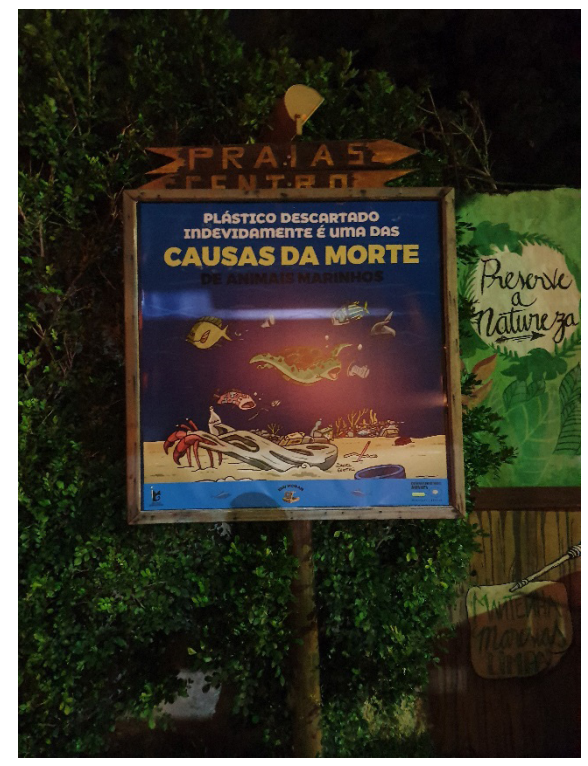

FONTE: ACERVO PESSOAL (2019) 
Faz-se importante considerar que muitas ações acabam sendo pontuais e não continuadas. Isso pode ser justificado pelo caráter sazonal da atividade turística em ambiente costeiro. É o caso, por exemplo, da campanha 'Ubatuba Sustentável' ação realizada em parceria entre o poder público e organizações não governamentais na temporada 2018-2019, com foco na separação seletiva do lixo. Nesta ação foram utilizadas tendas na praia de Ubatuba para abordagem dos turistas e ações expositivas sobre o lixo, além da capacitação de multiplicadores de informações (PREFEITURA MUNICIPAL DE UBATUBA, 2018).

Neste momento, é válido mencionar a teoria de Giddens (2001) que, afirma que as pessoas não têm consciência do porquê têm determinadas atitudes. Em outras palavras, e aplicando aos exemplos apresentados, o turismo aparece como um instrumento a partir do qual as pessoas passam a perceber e compreender determinadas situações vistas e vivenciadas no ambiente costeiro, e que podem não ter sido alvo de sua atenção no dia a dia. O turista, após tomar conhecimento da existência de lixo no mar, poderá ter atitudes mais conscientes inclusive ao retornar ao seu local de residência habitual.

As ações exemplificadas neste tópico, sejam elas iniciativas do terceiro setor com apoio ou não do governo, ou empreendidas pela iniciativa privada, abordam o problema do lixo no mar de forma a contribuir para a sensibilização com relação à redução da geração de lixo e cuidados com a destinação final. Consistem em intervenções humanas com o intuito de reduzir um impacto ambiental nocivo portanto, mitigadoras dos impactos socioambientais do lixo no mar.

\section{CONCLUSÃO}

Este artigo buscou discutir a relação entre o turismo em ambientes costeiros e o combate ao lixo que está no mar. Certamente, este tema de pesquisa (e outros relacionados) não irão se esgotar tão logo, pois cada vez mais têm sido alvo de pesquisas científicas e artigos que comprovam sua importância. O lixo existente nas praias e oceanos não é impactante apenas para o ambiente, e os estudos envolvendo a relação humana com a natureza, em todos os campos da ciência devem ser incentivados.

As informações apresentadas neste artigo demonstram que uma possível resolução para a presença de lixo no mar requer um entendimento sobre a dimensão social que envolve este problema ambiental. Buscou-se contextualizar a realidade da poluição dos mares e oceanos no planeta com ações e iniciativas empreendidas no âmbito do turismo, que podem até ser mitigadoras de danos ambientais originados das ações antrópicas, porém de forma alguma representam uma solução final e concreta para o complexo problema do lixo no mar.

Muitas ações apresentam um caráter socioambiental com relação ao comportamento dos turistas não apenas enquanto estão no ambiente costeiro, mas aos seus hábitos de consumo e consequente produção de lixo em qualquer ambiente. A contribuição dessa pesquisa ao tema proposto foi discutir e apresentar reflexões 
no âmbito do turismo a respeito do combate ao lixo que está no mar, identificando diferentes estratégias e instrumentos utilizados pela oferta turística para combater o problema do lixo no mar, contextualizadas de acordo com a realidade local em diferentes destinos. Ainda que sejam ações em nível local, podem representar um impacto em nível global, pois o expressivo fluxo de turistas em determinados destinos turísticos pode fazer com que as pessoas de fato sejam sensibilizadas e retornem com um comportamento de consumo mais consciente para seu local de residência habitual.

Ao pesquisar a relação entre turismo e o lixo no mar, observou-se que as ações empreendidas pela oferta turística podem contribuir para a diminuição dos resíduos sólidos, tangíveis, do ambiente natural. Porém, há que se considerar aqui uma limitação da pesquisa: a solução deste problema - o lixo no mar - é complexa, havendo múltiplas causas para a existência de lixo nos oceanos, assim como muitos fatores que afetam a natureza, variando em quantidade e distribuição de detritos em diferentes realidades e partes do mundo.

Portanto, o sucesso da implementação de qualquer ação voltada a solucionar o problema, dependerá de um trabalho interdisciplinar e da participação de toda a sociedade, civil, organizações governamentais e setor privado - seja em nível global, regional, nacional e local. É necessária uma constante reflexão sobre o mundo em que vivemos, de modo a relacionar ações e comportamento com o mundo em que desejamos viver.

Faz-se importante esclarecer que este artigo não teve como foco o volume de lixo gerado por parte dos turistas, ou a gestão local do lixo por parte do poder público durante períodos de alta temporada em destinos turísticos costeiros. Porém, há uma estreita relação entre essas questões. Sendo assim, e de modo a complementar a busca por soluções para combater o lixo no mar, sugere-se considerar, abordar e discutir esses dois temas em pesquisas futuras.

\section{REFERÊNCIAS}

ALVARES, P. B. Lixo turístico e a importância da gestão integrada de resíduos sólidos urbanos para um turismo sustentável: o caso de Caldas Novas, Goiás. 227 f. Dissertação (Mestrado em Desenvolvimento Sustentável). Universidade de Brasília, UnB. Brasília, 2010.

BAKER, A. Desperately Seeking Survival. Time. 04 de março de 2003. Disponível em: <http://content.time.com/time/magazine/article/0,9171,393799,00.html> Acesso em: 19 mar. 2021.

BRASIL. Lei 12.305, de 2 de agosto de 2010. Institui a Política Nacional de Resíduos Sólidos. Diário Oficial da União, Brasília, DF, 03/08/2010. Disponível em: <http://www2.mma.gov.br/port/conama/legiabre.cfm?codlegi=636> Acesso em 13 jan. 2020. 
BRASIL. Ministério do Meio Ambiente. Plano Nacional de Combate ao Lixo no Mar. Brasília, 2019.

BRUDEKI, N. M. A exploração econômica do setor de turismo e os efeitos nos serviços sanitários do litoral paranaense. Caderno Virtual de Turismo, Rio de Janeiro, v. 6, n. 4, p. 69-78, 2006.

CUNHA, S. K; CUNHA, J. C. Competitividade e sustentabilidade de um cluster de turismo: uma proposta de modelo sistêmico de medida de impacto do turismo no desenvolvimento local. Revista de Administração Contemporânea, Curitiba, v. 9 n. 2, p. 110-124. 2005.

ESPÍNOLA, R. S., FERREIRA, L. V. F.,; MARQUES JUNIOR, S. A certificação Bandeira Azul e seus impactos nas praias do Brasil. Revista Turismo Em Análise, São Paulo, v. 31, n. 3, p. 561-576, set./dez. 2020.

FRANZ, B. O lixo flutuante em regiões metropolitanas costeiras no âmbito de políticas públicas: o caso da cidade do Rio de Janeiro. 150 f. Tese (Doutorado em Planejamento Energético) - Instituto Alberto Luiz Coimbra de Pós Graduação e Pesquisa de Engenharia, Universidade Federal do Rio de Janeiro, 2011.

FREDIANI, F. Poluição da Natureza: depoimento de uma cidade litorânea. São Paulo, 2020. Palestra proferida no evento on-line Encontro Lixo Zero: lixo, sintoma de quê?.

FIFTH INTERNATIONAL MARINE DEBRIS CONFERENCE (IMDC). A estratégia de Honolulu. 2011. Disponível em: < https://5imdc.wordpress.com/about/ honolulustrategy/>. Acesso em: 03 mai. 2019.

GIDDENS, A. Em defesa da sociologia: ensaios, interpretações e tréplicas. São Paulo: Editora UNESP, 2001.

GUERREIRO, D.; PACHECO, A. A living lab for the sustainable energy transition ambition of the Algarve Region's S3. European Commission. Portugal, Algarve, 2020. Disponível em <https://s3platform.jrc.ec.europa.eu/-/a-living-lab-for-thesustainable-energy-transition-ambition-of-the-algarve-region-s-s3> Acesso em: 07 abr. 2021.

LEFF, E. La apuesta por la vida: imaginación sociológica e imaginarios sociales em los territorios ambientales del sur. México: Siglo XXI Editores, 2014.

MARINE LITTER NETWORK. Disponível em <http://marinelitternetwork.com/> Acesso em 02/05/2019. 
MEDEIROS, L. C.; MORAES, P. E. S. Turismo e sustentabilidade ambiental: referências para o desenvolvimento de um turismo sustentável. Revista Meio Ambiente e Sustentabilidade. Curitiba, v. 3, n. 2, p. 197-234, jan./jun. 2013.

OLIVEIRA, D. P.; COSTA, G. B. O turismo e a sua implicação ambiental: análise a partir da observação do uso turístico - o caso de Faro, Portugal. Ilhas Canárias, Espanha. Pasos, v. 18, n 2, p. 279-291, abr./jun. 2020.

ORGANIZAÇÃO MUNDIAL DO TURISMO (OMT). Tourism for SDGS. Disponível em: <http://tourism4sdgs.org/>. Acesso em: 04 jun. 2020.

NAÇÕES UNIDAS NO BRASIL (ONU). 10 atitudes que você pode tomar para salvar os oceanos. Disponível em: <https://nacoesunidas.org/onu-10-atitudes-quevoce-pode-tomar-salvar-oceanos/> Publicado em 03 jan. 2018. Acesso em 10 ago. 2020.

Campanha Mares Limpos celebra dois anos de atividades contra o lixo plástico. Disponível em: < https://nacoesunidas.org/campanha-mares-limposcelebra-dois-anos-de-atividades-contra-o-lixo-plastico/> Publicado em 26 de fevereiro de 2019. Acesso em: 03 mai. 2019.

Transformando nosso mundo: a agenda 2030 para o desenvolvimento sustentável. Traduzido pelo Centro de Informação das Nações Unidas para o Brasil. Rio de Janeiro: UNIC, 2015.

PIERRI, N. et al. A ocupação e uso do solo no litoral paranaense: condicionantes, conflitos e tendências. Desenvolvimento e meio ambiente, $n^{\circ} 13$, p. 137-167. Curitiba, 2006.

POIATO RECICLA. Poiato Recicla no litoral norte de São Paulo. Disponível em < https://poiatorecicla.com.br/poiato-recicla-no-litoral-norte-de-sao-paulo/> Acesso em: 07 abr. 2021.

PREFEITURA MUNICIPAL DE UBATUBA. Prefeitura e sociedade civil discutem Projeto "Ubatuba Sustentável”. Disponível em < Prefeitura e sociedade civil discutem Projeto "Ubatuba Sustentável" - Prefeitura Municipal de Ubatuba> Acesso: 10 mar. 2021.

SAMPAIO, C. A. C.; ZAMIGNAN, G. Estudo da demanda turística: experiência de turismo comunitário da microbacia do Rio Sagrado, Morretes (PR). Cultur. Revista de Turismo e Cultura, ano 06, nº1, fev. 2012.

SANTOS, J. G.; CÂNDIDO, G. A. A (in)sustentabilidade ambiental das atividades turísticas da "melhor praia do Brasil": um estudo de caso em Porto de Galinhas, PE. In: PERNA, F.; GOUVEIA, P.; SERRA, F.; SANTOS, J.; ÁGUAS, P. Economia, ambiente e sustentabilidade no turismo. Faro, Portugal: UAlg ESGHT, 2013. 
SUSTOWNS. Interreg Mediterranean. Disponível em <https://sustowns.interregmed.eu/> Acesso: 07 abr. 2021.

UNITED NATIONS ENVIRONMENT PROGRAM (UNEP). Global Waste Management Outlook. [S.I.] UNESCO, 2015.

VELIS C., LERPINIERE, D., TSAKONA, M. Previna o lixo marinho plástico - agora! Uma parceria facilitada pela ISWA para evitar o lixo marinho, com um chamado global para a ação para investir em gestão sustentável de resíduos e recursos em todo o mundo. Relatório elaborado em nome da International Solid Waste Association (ISWA). Um produto da Força-Tarefa de Lixo Marinho. ISWA, set. 2017. Viena, pp.75. Disponível em: <http://marinelitter.iswa.org/marine-task-forcereport-2017/> Acesso em: 10 mar. 2021.

Recebido em: 01-11-2020. Aprovado em: 22-05-2021. 
$S$ 